\title{
International Cultural Heritage Law (2018)
}

\author{
Flavia Zorzi Giustiniani*
}

\section{Decision 13 Cом 11 on Intangible Cultural Heritage in Emergencies}

Recently, discussions on 'Intangible Cultural Heritage (ICH) in emergencies' have started within the Intergovernmental Committee for the Safeguarding of the Intangible Cultural Heritage ${ }^{1}$ which, since its 11th session, highlights the ever increasing importance attributed to ICH in the context of natural disasters. ${ }^{2}$ Such a global initiative was launched to better understand the role of ICH in emergencies and, to this aim, to gain knowledge and experience on the role of communities in both safeguarding their ICH at risk in emergencies and mobilizing the latter as a tool for preparedness, resilience, reconciliation and recovery. Decision 13, adopted by the Committee during its 13th session in Port Louis, constitutes the latest effort in this regard. ${ }^{3}$

As far as disasters are concerned, Decision 13 also builds upon the Addendum to the Strategy for the Reinforcement of Unesco's Action for the Protection of Culture and the Promotion of Cultural Pluralism in the Event of Armed Conflict, concerning emergencies associated with disasters caused by natural and human-induced hazards. ${ }^{4}$ This addendum crucially adapts the international DRR policy framework to the whole cultural domain, instead that to World Heritage alone, as it was the case earlier. In this respect, inventories of IC $\mathrm{H}$ are playing an increasingly important role.

The development of inventories of IC $\mathrm{H}$ is one of the first and clearest obligations established by the Convention for the Safeguarding of Intangible Cultural Heritage, since ICH cannot be protected if it is not specified what specific

* Assistant Professor of International Law, Uninettuno University.

1 The Committee was established under the Convention for the Safeguarding of the Intangible Cultural Heritage.

2 Intergovernmental Committee for the Safeguarding of the Intangible Cultural Heritage, 'Item 11 of the Provisional Agenda: Intangible Cultural Heritage in Emergencies, Thirteenth Session' (26 November-1 December 2018).

3 Intergovernmental Committee for the Safeguarding of the Intangible Cultural Heritage, 'Decision 13.Сом 11 on Intangible cultural heritage in Emergencies', Thirteenth session (26 November-1 December 2018) ITH/18/13.COM/11.

4 Unesco, 'Strategy for the Reinforcement of Unesco's Action for the Protection of Culture and the Promotion of Cultural Pluralism in the Event of Armed Conflict', Annex I. Adden$\operatorname{dum}(14$ November 2017), available at <https://unesdoc.unesco.org/ark:/48223/pfoooo259805> last accessed (as any subsequent URL) on 28 June 2019. 
elements comprise it. The Convention, however, does not establish criteria on how to make such inventories. It only provides, in its art. 12, that ' $[t]$ o ensure identification with a view to safeguarding, each State Party shall draw up, in a manner geared to its own situation, one or more inventories of the intangible cultural heritage present in its territory'. ${ }^{5}$ These inventories should be updated regularly and each member state, when submitting its periodic report to the Committee, must provide data about them.

In order to advise State parties, non-governmental organizations and communities on the process of inventorying ICH and the preparation of inventories, at its tenth session the Intergovernmental Committee charged the Secretariat of the Convention to prepare a guidance note for inventorying cultural heritage, ${ }^{6}$ which was released in October $2017 .{ }^{7}$ The note outlines a set of guiding principles and recommendations that should be utilized by states as a source of inspiration when drawing up new inventories or revising existing ones. It bears noting that the respect of these principles, which focus inter alia on the importance of the consent and the involvement of the communities and individuals concerned, has a bearing - though indirect - on the listing at international level. Later, at its twelfth session in 2017 the Committee also requested the Secretariat to consider integrating disaster risk management into the Guidance Note for inventorying intangible cultural heritage and related capacity-building training materials. ${ }^{8}$ Such integration, which has not been realized yet, is considered crucial in order to ensure a proper safeguarding of ICH against disasters.

Against this background, Decision 13 ' $\left[\mathrm{r}\right.$ ] ${ }^{2}$ iterates the need to foster the links between disaster risk reduction and inventories of intangible cultural heritage and invites State parties to refer to the guidance note on inventorying intangible

5 A guidance on the process through which inventories should be prepared can be found in the Operational Directives of the ICH Convention. See General Assembly of the States Parties to the Convention, 'Operational Directives for the Implementation of the Convention for the Safeguarding of the Intangible Cultural Heritage', Second Session (16-19 June 2008), which was amended at its Third Session (22-24 June 2010), its Fourth Session (4-8 June 2012), its Fifth Session (2-4 June 2014) and its Sixth Session (30 May-1 June 2016), Chapters VI.3 and VI.4.

6 See Intergovernmental Committee for the Safeguarding of the Intangible Cultural Heritage, 'Decision 10.Сом 10, Tenth session' (30 November-4 December 2015) ITH/15/10.COM/10, para 23 .

7 See unesco, 'Guidance Note on Inventorying Cultural Heritage', available at $<$ https://ich .unesco.org/doc/src/Guidance_note_on_inventorying_EN.pdf>.

8 See Intergovernmental Committee for the Safeguarding of the Intangible Cultural Heritage, 'Decision 12.COM 15, Twelfth Session' (4-9 December 2017) ITH/17/12.COM/15, para. 9 . 
cultural heritage.' ${ }^{9}$ The Decision also charges the Secretariat to organize during the course of 2019 an expert meeting to define, based on the knowledge and experience acquired, the operational modalities for the safeguarding of $\mathrm{ICH}$ in emergencies. ${ }^{10}$

\section{Position Paper on Culture in City Reconstruction and Recovery (CURE)}

In November 2018 Un ESCO and the World Bank published a Position Paper on 'Culture in City Reconstruction and Recovery' (CURE). ${ }^{11}$ CURE is part of a broader initiative following the signing of a Memorandum of Understanding between the two organizations in July $2017,^{12}$ which focused on urban regeneration and historic urban landscapes, the cultural and creative industries, as well as resilience and disaster risk management, with culture as a driver. The Position Paper offers a framework on CURE and operational guidance for policymakers and practitioners - especially the World Bank and UNESCO staff operating in this field - for the planning, financing, and implementation phases of post-conflict, post-disaster and post-crisis city reconstruction and recovery processes.

CURE starts from the observation that natural disasters, whose frequency and intensity are dramatically growing also as a consequence of climate change, as well as armed conflicts are affecting more and more urban areas. All this happens in an age of increasing and unstoppable urbanization, with the prediction that by 2050 more than two-thirds of the world's population will live in cities. In order to better manage the impact of such factors, the World Bank and UNESCO have elaborated a framework that puts culture at the centre, being convinced that the latter is crucial to achieve sustainable urban development and to ensure effective post-crisis reconstruction and recovery processes. This framework integrates both people-centered and place-based approaches into policies that share a common cultural thread. The final objective is that of making cities more inclusive, safe, resilient, and sustainable.

9 See Intergovernmental Committee for the Safeguarding of the Intangible Cultural Heritage (n. 3) para. 7 .

$10 \quad$ Ibid., para. 9 .

11 The Paper is available at <https://openknowledge.worldbank.org/handle/10986/30733>.

12 See International Development Association, 'Memorandum of Understanding between United Nations Educational, Scientific and Cultural Organization and International Bank for Reconstruction and Development' (13 July 2017), available at <http://www.unesco.org/ new/fileadmin/MULTIMEDIA/HQ/BSP/pdf/MOUUNESCOWorldBank2017.pdf>. 
As far as disasters are concerned, it should be remembered that the Sendai Framework for Disaster Risk Reduction 2015-2030 (SFDRR) has placed a special emphasis on recovery through the concept of Build Back Better. Such concept is incorporated in Priority 4 which, remarking the growing impact of natural disasters, invites states to 'further strengthen disaster preparedness for response, take action in anticipation of events, integrate disaster risk reduction in response preparedness and ensure that capacities are in place for effective response and recovery at all levels'.13 Moreover, since 2008 the United Nations, the World Bank and the European Union, on the basis of a joint declaration, ${ }^{14}$ have been working together to assist countries recovering from natural disasters or conflict-related crises. This common approach to postdisaster and post-conflict management is guided respectively by Post Disaster Needs Assessments (PDNA) in countries recovering from natural disasters, and Recovery and Peacebuilding Assessments (RPBA) in countries recovering from conflicts. PDNAs have then been complemented, in 2015, by a Guide to Developing Disaster Recovery Frameworks, a practice-based and results-focused tool assisting governments and other stakeholders in formulating a framework for the medium- to long-term post-disaster recovery. ${ }^{15}$

In order to render cities more resilient (and thus less vulnerable), more inclusive and more sustainable, it is crucial to mainstream culture into reconstruction and recovery processes. Various international frameworks adopted

13 See Third United Nations World Conference on Disaster Risk Reduction, 'Sendai Framework for Disaster Risk Reduction 2015-203o' (14-18 March 2015), para. 32 ('Priority 4: Enhancing Disaster Preparedness for Effective Response and to Build Back Better in Recovery, Rehabilitation and Reconstruction'), available at <https://www.unisdr.org/ files/43291_sendaiframeworkfordrren.pdf >. According to the General Assembly, Build Back Better consists of ' $[t]$ he use of the recovery, rehabilitation and reconstruction phases after a disaster to increase the resilience of nations and communities through integrating disaster risk reduction measures into the restoration of physical infrastructure and societal systems, and into the revitalization of livelihoods, economies and the environment'. See UnGA, 'Report of the Open-ended Intergovernmental Expert Working Group on Indicators and Terminology Relating to Disaster Risk Reduction' (1 December 2016) UN Doc A/71/644, v, 11.

14 European Commission, UN Development Group, World Bank, 'Joint Declaration on PostCrisis Assessments and Recovery Planning' (25 September 2008), available at $<$ http:// www.un.org/ga/search/view_doc.asp?symbol=A/RES/70/1\&Lang=E $>$.

15 See GFDDR, World Bank Group, EU, UndP, 'Guide to Developing Disaster Recovery Frameworks. Sendai Conference Version' (March 2015), available at <https://www.gfdrr .org/sites/default/files/publication/DRF-Guide.pdf >. The Guide was applied the same year of its release by the Nepalese authorities after the devastating earthquake that struck their country. See Government Of Nepal National Planning Commission, Nepal Earthquake 2015 Post Disaster Needs Assessment. Vol A: Key Findings (Kathmandu 2015) 15. 
recently contain recommendations, as well as detailed guidelines, on how to integrate culture in such processes. The SFDRR, for instance, draws the attention of national and worldwide policies to the links between the protection of cultural heritage and territorial resilience. ${ }^{16}$ More crucially, in 2015 culture was mainstreamed for the first time in the international development agenda. This happened with the adoption of the 2030 Agenda for Sustainable Development, ${ }^{17}$ which inter alia considers cultural and natural heritage as essential tools in order to achieve sustainable development. ${ }^{18}$ Other international frameworks that bear noting are the New Urban Agenda ${ }^{19}$ and the UnEsCo Recommendation on the Historic Urban Landscape. ${ }^{20}$

A common feature of all the cited frameworks is that the role of culture, though being recognized, is still marginal, while there is a certain disconnect between place-based and people-centered policies in post-crisis city reconstruction and recovery. Against this background, the CURE Framework is meant to bridge the said gaps. This is achieved through the mainstreaming of culture into all areas of intervention and across all phases of reconstruction and recovery, with policies that integrate in a coherent strategy people's needs and place characteristics. With respect to earlier strategies, the focus is not limited to the recovery of tangible cultural assets, such as architectural buildings, but rather is extended to local knowledge and practices and other manifestations of intangible heritage, as well as to cultural and creative industries.

Drawing from global experience and some successful cases, the CURE Framework enunciates seven key principles, which provide as follows: (1) acknowledging the city as a 'cultural construct' where built structures and open spaces are closely linked to the social fabric; (2) starting the reconciliation process with the (re)construction of cultural landmarks and places of significance to local communities; (3) fostering cultural expressions to offer appropriate ways to deal with post-crisis trauma and reconcile affected communities;

$16 \quad$ Specific mentions to culture are contained in para. 3 point (c), Priority Area 1 point (d) and Priority Area 3 point (d).

17 See UNGa Res 70/1 (21 October 2015) UN Doc A/RES/70/1.

18 See Goal 11 ('to make cities and human settlements inclusive, safe, resilient, and sustainable'), Target 11.4.

19 See Third UN Conference on Housing and Sustainable Urban Development, 'New Urban Agenda' (2o October 2016), available at <http://habitat3.org/wp-content/uploads/NUA -English.pdf $>$. The Agenda was subsequently endorsed by the United Nations General Assembly at its sixty-eighth plenary meeting of the seventy-first session on 23 December 2016.

20 UNEsco General Conference, 'Recommendation on the Historic Urban Landscape' (10 November 2011), available at <https://whc.unesco.org/uploads/activities/documents/ac tivity-638-98.pdf>. 
(4) prioritizing culture early in the planning process, starting with needs assessments and the implementation of emergency interventions that reflect community priorities; (5) engaging communities and local governments in every step of the recovery process; (6) using finance models that balance immediate/short-term needs with the medium/long-term development timeframe of reconstruction plans; (7) using finance models that balance immediate/ short-term needs with the medium/long-term development timeframe of reconstruction plans. These principles, which are all founded on culture, should guide action through reconstruction and recovery, from the damage and needs assessment to the implementation phases. The expected result is to strengthen the perception of inclusion of communities and their identities and to improve social and economic sustainability in urban areas.

\section{Warsaw Recommendation on Recovery and Reconstruction of Cultural Heritage}

The Warsaw Recommendation ${ }^{21}$ was adopted at the International Conference 'The challenges of World Heritage recovery: International Conference on Reconstruction', which was jointly organized by the Polish authorities and UNEsco and, according to the decision of the 41st session of the World Heritage Committee (WHC), ${ }^{22}$ took place in the Royal Castle in Warsaw on 6-8 May 2018. The document constitutes the most significant achievement of the conference, formally recognizing as it does for the first time that the recovery and reconstruction of World Heritage properties following armed conflicts or natural disasters also concern social, economic, humanitarian and human rights' considerations. ${ }^{23}$ The Recommendation was adopted and recommended for

21 The document is available at <https://whc.unesco.org/en/news/1826/>.

22 See wHC, 'Decision 41.COM 7 , State of Conservation of the Properties Inscribed on the World Heritage List', Forty-first session (2-12 July 2017) WHC/17/41.COM/7. See also WHC, 'Decision 40 COM 7, State of Conservation of World Heritage Properties' (10-20 July 2016) $\mathrm{WHC} / 16 / 40 . \mathrm{COM} / 7$.

23 This is also in line with the general trend within the WH Convention. See e.g. WHC, 'Decision 40 сом 5 C, World Heritage Convention and Sustainable Development' (10-20 July 2016) WHC/16/40.COM $/ 5 \mathrm{C}$, para. 3 , welcoming the adoption of the Policy Document for the integration of a sustainable development perspective into the processes of the World Heritage Convention by the 2oth General Assembly of States Parties in 2015; and UNESCO, 'Strategy for the Reinforcement of the Organization's Actions for the Protection of Culture and the Promotion of Cultural Pluralism in the Event of Armed Conflict', adopted in November 2015 by the 38 th General Conference of UNESCO $\left(38 / \mathrm{C}_{4} 8\right)$, to strengthen linkages 
widespread dissemination during the 42nd session of the WHC in Bahrain, in June 2018.

The document acknowledges the value of $\mathrm{CH}$ during peacebuilding as well as post-disaster recovery and reconstruction and calls for the full participation of the communities concerned in a decision-making process that regards their cultural life and heritage. ${ }^{24}$ In the second place, it emphasizes the need to allow sufficient 'time for reflection' in order to address and assess the real needs of societies in the context of post-conflict and post-disaster recovery and reconstruction. ${ }^{25}$ Last but not least, the Recommendation stresses the importance of 'building resilience' to address destruction and disasters, as well as of reducing existing vulnerabilities - including by building back better - in reconstructing heritage and of 'invest[ing] in long term capacity building in disaster risk management and conservation techniques. ${ }^{26}$ A series of recommendations are then separately addressed to the various international actors involved. ${ }^{27}$ Inter alia, the World Heritage Committee is asked to take account of the principles listed in the document to develop guidance for reconstruction and recovery at World Heritage sites, including Resource Manuals, further development of case studies and best practice examples. State parties to the World Heritage Convention are instead advised to use the Historic Urban Landscape (HUL) and integrated management approaches to achieve a holistic approach to reconstruction for post disaster recovery.

\footnotetext{
between culture and heritage, on one hand, and humanitarian, security, peacebuilding and in general development considerations, on the other hand.

24 See Warsaw Recommendation (n. 21) 3.

25 Ibid.

26 Ibid, 4.

27 Ibid, 5 .
} 